\title{
ADMINISTRACIÓN DEL REINO DE NAVARRA EN LA ETAPA DE LOS AUSTRIAS.
}

por

\author{
MARÍA ISABEL OSTOLAZA ElIZONDO \\ Universidad Pública de Navarra
}

RESUMEN: El conocimiento de las instituciones de gobierno y administración de Navarra en la etapa de los Austrias a través de la bistoriografía autóctona o de la de autores foráneos, corre el riesgo de ser excesivamente simplista por carencias informativas importantes en la consulta de fuenter arcbivisticas.

El objetivo de este trabajo, es el de poner en relación la documentación existente en el Arcbivo General de Navarra, con la de otros arcbivos estatales, especialmente la referente a los fondos de Consejos de Cámara y Estado conservados en Simancas y en el Archivo Histórico Nacional. A través de su cotejo quedan en entredicbo ciertos tópicos sobre la singularidad de Navarra y su tratamiento especial en temas de gobernabilidad y administración en relación con otros territorios de La monarquía hispánica.

Al mismo tiempo se estudian otras facestas de actuación del Consejo real de Navarra, que permiten potenciarlo al mismo nivel que otras consejos territoriales, añadiendo a su faceta de tribunal superior de administración de justicia en el Reino, el de brgano informador de los grandes Consejos de la Conna, colaborador con el virrey en sus tareas de gobierno politico, y brazo ejecutor de la monarquia en materias de gobiemo y justicia.

Pal.abras cunve: Navarra. Consejos de Cámara y Estado. Consejo de Navarra. Virrey.

ABSTRACT: Our knowledge of the institutions of government and administration in Navarre under the Austrias runs the risk of being simplistic because of a lack of important information drawn from arcbival sources. The aim of this article is to relate the documentation in the Archivo General de Navarra to that of other state archiver, especially the boldings of Consejos de Camara y Estado at Simancas and the Arcbivo Historico Nacional. The comparison raxises serious questions about the singularity of Navarre and its special treatment in relation to otber territories of the Spanish monarchy. At the same time, otber aspects of the royal council in Navarre are studied, which allow it to be brought to the same lavel as otber royal councils, adding to its 
role as supreme judicial tribunal that of an informing organ of the great councils of the Spanish crown, collaborator with the viceroy in bis political government, and executive arm of the monarchy in government and justice.

KEY wOrDS: Navarra. Councils of Navarra and State. Council of Navarra. Virrey.

\section{I.1. ESTADO DE LA CUESTIÓN. LOS ÓRGANOS SINODALES.}

La valoración de las instituciones del reino de Navarra en la E. Moderna, ha estado supeditada a la de los Consejos que desde la corte tuvieron que ver con la administración del mismo, cuando tras las cortes de Burgos de 1515 quedó unido políticamente a la Corona de Castilla. Un seguimiento de lo publicado por historiadores del Derecho, o por profesionales del sector de archivos, nos permite detectar lagunas informativas que les llevan a apreciaciones que parecen situar al Reino en una situación de excepcionalidad en relación con las formas de gobierno de los demás territorios peninsulares de la monarquía hispánica.

El Consejo de Navarra es conocido sobre todo a través de la obra de Salcedo, que describe su funcionamiento en el s. XVI. Poco reconocido por los tratadistas del s. XVII, no llama tampoco la atención de estudiosos más recientes, que justifican el escaso interés de este organismo en base a que «el Consejo de Navarra fue un organo más judicial que político, y por ello ni los autores del s. XVII hablaron de él al ocuparse de los Consejos»!

Entre ellos, uno de los que más estudiados últimamente es el Consejo de Cámara de Castilla, del que con relación a Navarra se llega a decir refiriendose al s. XVII: «Las relaciones de la Cámara de Castilla con el Reino de Navarra exceden del marco funcional tradicional de la Cámara ${ }^{2}$. En el afan por destacar el papel de la Cámara y en el marco del procedimiento legislativo del s. XVIII, se insiste $\alpha$ Hay que enmarcar el becho de que las comunicaciones de las disposiciones reales al Reino de Navarra no seguían la vía comín (Consejo de Castilla, escribanía de Gobierno), sino la vía especial de Cámara de Castilla, a través de la Secretaría de Gracia y Justicia de Castillaw ${ }^{3}$.

\footnotetext{
1 Hago la precisión de que descarto por su escaso interés las menciones que sobre este órgano aparecen en los manuales de Historia del Derecho en curso, limitandone a aquellos autores que cuando menos hacen alguna valoración sobre el organismo. TOMAS Y VALIENTE, Fr: Las institucioner situadas en el ambito de la monarquia, bispánica de Pelipe IV: el gobierno de La monarquia, la crisis de 1640 $y$ el fracaso de la begemonia europea. (Historia de España, t. 25). Madrid: Espasa Calpe, 1987 pp. $83-$ 174 , nota 5 .

2 Alvarez-Coca Gonzalez, M.J.: La Cámara de Castilla. Inventario de los libros de la secretaria de Gracia y Justicia que se conservan en el Arbito Historrico Nacional, Madrid: Dirección de Archivos Estatales, 1993, p. 41.

3 CABrera BosCh, M.I.: El consejo real de Castilla y la ley. (Biblioteca de Historia, n ${ }^{\circ} 19$ ), Madrid: C.S.I.C., 1993, p. 161.

Hispania, LX/2, núm. 205 (2000) 563-596
} 
De todo ello parece deducirse que el reino de Navarra fue gobernado y administrado de forma singular, y como no se encuentran mejores argumentos para justificarlo, se buscan razones en la foralidad del territorio, como si este hecho fuera privativo de Navarra, incluso tras la pérdida por la Corona de Aragón de sus instituciones por el apoyo prestado a la causa del archiduque de Austria en la guerra de Sucesión española.

Afirmaciones todas ellas que pueden inducir a equívocos a la hora de buscar fuentes de información histórica, como si la Cámara fuera el único o cuando menos el más importante de los organismos de conexión entre la corona de Castilla y el reino de Navarra. En este sentido tengo que manifestar que los datos publicados sobre fuentes archivísticas me llevaron a una zona de agujeros negros informativos, en especial en lo referente a la documentación remitida por el virrey en sus funciones de gobierno político del reino, que no dejaba rastro en la Cámara.

Por ello hay que advertir que el énfasis puesto en algunos instrumentos de descripción archivística tratando de destacar la importancia de los cedularios conocidos como Libros de Navarra (repartidos entre Simancas y el AHN en el fondo Cámara de Castilla), puede alterar el sentido de ciertas citas, atribuyendo a la Cámara cuestiones relacionadas en realidad con el Consejo de Castilla. Así se entresaca de Juan de Moriana y su Discurso sobre el Consejo (de Castilla) y ceremonial del mismo de 1654: «Están subordinados a este Consejo el Reyno de Navarra y todos los negocios de los tribunales supremos que de él vienen por vía de apelación: esto es en materia de las cosas de las Cortes de aquel Reino, y de bazienda real y cosas que tocan al govierno*'.

Evidentemente la cita original alude al Consejo de Castilla en la faceta relacionada con la administración de justicia, independientemente de la materia tratada en los asuntos contenciosos que pueden ser entre otros, determinados agravios presentados por las Cortes por conculcarse el Fuero y leyes del reino, $o$ respecto a la aplicación de las regalías en hacienda y patrimonio real, o temas de gobierno interior que corresponden a la sala de gobierno del Consejo de Castilla.

A mi parecer, identificar a Navarra como un reino especial, con una casi exclusiva dependencia institucional de la Cámara de Castilla, es bastante peligroso. Las mismas fuentes de información archivística indican que algunos territorios además de Navarra, tuvieron organizada la documentación relacionada con la Cámara, en libros cedularios específicos y separados de los del reino de Castilla: así los del reino de Granada desde 1490-1609, y Aragón desde 1508-15265. Respecto a temas de patronato eclesiástico, la instrucción de Feli-

\footnotetext{
1 Alvarez-Coca Gonzalez, M.J.: La Cámara, p. 41, citando a S. DE Dios, Fuentes para el estudio del Consejo real de Castilla. Salamanca: Dipucación Provincial, 1986, pp. 217-349.

3 De la Plaza Bores, A.: Guia del investigador. Arcbivo General de Simancas, $3^{\circ}$ edic. Madtid: Ministerio de Cultura, Dccon. Gral. de Bellas Artes y Archivos, Dccon. de Archivos Estatales, 1986, p. 150.
} 
pe II de 6-1-1588 ordena que la Cámara vea *los negocios tocantes a mi patronazgo real de la Iglesia en estos mis reinos de Castilla, y el de Navarra y islas de Canaria, de cualquier calidad que sean, asi los que fueren de justicia como de gracia» ${ }^{6}$.

Por tanto queda descartada la excepcionalidad de Navarra y el tratamiento dado por la Cámara, en relación con otros territorios ligados a la corona de Castilla por derecho de conquista y adscripción política. Respecto a las atribuciones de la Cámara, es evidente que sus orígenes están muy ligados al Consejo real, aunque la regulación de sus funciones no se realice hasta la segunda mitad del s. XVI. Lo que no quiere decir que la Cámara no actuara como órgano instructor de las facultades regias de gracia, merced y real patronato antes de la elaboración de las distintas Instrucciones que irán aquilatando sus competencias.

Entre ellas la emitida en $1559^{7}$, siguiendole la de 1588 que como señala Delgado Barrado ${ }^{8}$, fue conocida a través de la obra de J. Fayard ${ }^{9}$, que fue la primera que mencionó la tan traída y llevada instrucción de 1588 considerada como una de las más importantes, aunque en palabras de uno de los grandes archiveros de Simancas «ni especifica el número de individuos que ban de formar la Cámara, ni todos los asuntos de que se ba de ocupar, limitandose a fijar con claridad que debiera ser presidida por el presidente del Consejo (de Castilla), y que (la Cámara) entenderá en todos los asuntos de Patronato y en la provisión de cargos de justicia, sin enumerar otras funciones que fueron siempre y continuaron siendo de su competenciax ${ }^{10}$.

Ratificada por la instrucción de 1592 a fines del reinado de Felipe II, se reitera el papel de la Cámara en los asuntos de Gracia, Justicia y Real Patronato. Asímismo en tiempo de Felipe III en 1603 se vuelve a hacer hincapié sobre las competencias y asuntos dependientes de la Cámara, que se verá desbordada por la cantidad de memoriales y peticiones de particulares que se reciben en este reinado. Para etapas posteriores no hay estudios sobre la Cámara, y me remito a las palabras de Delgado Barrado que afirma: «poco sabemos del reinado de Felipe IV y Carlos II en orden a este procesow.

Analizando la documentación referente a Navarra anterior a 1588, se observa que las atribuciones de la Cámara fueron mayores que la administración de las regalías de la Corona en materia de gracia, justicia y patronato real. Probablemente no estaban deslindadas las competencias del Consejo de Castilla en materia de gobierno interior. Por el contrario la Cámara se ciñó posteriormente a lo que se le señala en la instrucción de 1588 , aunque perdió operatividad desde el s. XVII por las diversas Juntas generales y las más específicas sobre

6 Idem, p. 145.

7 Escudero, J.A.: Los secretarios de Estado y de Despacho, en Estudios de la Administración. Madrid: Instituto de Estudios Administrativos, t. 3, 1969, Pp. 749-757.

8 Delgado BARRADO, J.M.: La Cámara de Castilla: fuentes legislativas para un estudio institucional (1442-1759), en Hispania, 1992, $\mathrm{n}^{\circ} 180$, pp. 59-81.

9 FAYARD, J.: Los miembros del Consejo de Castilla (1621-1746), $2^{\circ}$ edic. eraducida. Madrid: Siglo XXI, 1982.

10 De la Plaza Bores, A.: Guia del investigador. Arcbivo General de Simancas, p. 145. 
temas de guerra, hacienda, etc. que se fueron constituyendo a lo largo de esta centuria.

A pesar de salirme de ámbito cronológico de este trabajo, no puedo dejar de mencionar el texto de Garma Y Duran sobre la Secretaría de Gracia en el s. XVIII, tan citado por los Historiadores del Derecho cuando tratan de la situación de Navarra. Sus afirmaciones sobre el gobierno político del Reino deben matizarse: "Corre tambien por ella y se expide todo lo perteneciente al govierno politico del Reyno de Navarra y las pretensiones de sus naturales; los llamamiento a las Cortes y sus convocatorias; exempcion de quarteles y alcavales; erecciones de palacios de cabo de armeria.... y todos los demas negocios $y$ dependencias de que conoce privativamente la Cámara; $Y$ assi se dan las cédulas para que se cumplan y guarden los despacbos que se expiden por los demas tribunales y ministross 11 .

Las matizaciones afectan al párrafo destacado en negrita especialmente en lo referente al todo, y en cuanto a las pretensiones de sus naturales intentaremos explicar su significado al dilucidar las competencias y procedimiento de actuación de la Cámara en las páginas siguientes.

Para finalizar este apartado sobre el estado de la cuestión, tengo que hacer referencia a la historiografia navarta advirtiendo que no ha tocado o apenas, otra documentación que la del Archivo General de Navarra. No se ha realizado un seguimiento sistemático de los fondos de Consejos, probablemente porque hasta hace poco tiempo eran poco menos que inaccesibles por lo desorganizados que estaban. Afortunadamente el panorama ha cambiado a partir de los años 90, y la publicación de obras como la de M.J. Alvarez-Coca ya mencionada, han permitido conocer la existencia de series sistemáticas de documentación relacionada con los distintos Consejos de la monarquía austriaca y Navarra.

La institución más trabajada ha sido sin duda alguna el Consejo de Navatra. Como precedente puede consultarse el artículo de L.J. Fortún, que nos permite conocer la composición y actividades de Consejo real en la baja E. Media y especialmente en el momento crítico de la conquista e incorporación de Navarra a Castilla ${ }^{12}$. Apenas nada que ver con la composición y atribuciones del organismo despues de la visita del Ldo. Valdés, en la que se da un giro importante tratando de equipararlo en lo judicial a la chancillería de Valladolid, y en lo político a los restantes Consejos territoriales peninsulares. Por ello sigue siendo imprescindible la consulta de la obra de Salcedo, que se basa en docamentación exclusiva de archivos navarros, y en especial en las llamadas Ordenanzas del Consejo publicadas en $1622^{13}$.

"Garma y Duran, Fco Javier: Theatro Universal de España. Descripción eclesiástica y secular de sados sus Reynos y provincias en general y en particular. Madrid: Imp. de Mauro Marti, 1751, vol. 4, pp. 224-225.

12 FORTUN PEREZ DE CIRIZA, L.J.: El Consejo real de Navarra entre 1494-1525, Príncipe de Viana, Homenaje a Lacarra, t. I, 1986, pp. 165-180.

13 Ordenanzas del Consejo de Reyno de Navarra. Pamplona: Nicolás de Assiayn, 1622. 
Sobre el s. XVII M.D. Martínez Arce elaboró una Tesis doctoral, defendida en la Universidad de Navarra en 1994 y todavía inédita, de cuya existencia nos da noticias la propia autora, que ha dado a conocer alguno de sus capítulos en otras publicaciones ${ }^{14}$.

En realidad la Cámara fue un órgano con competencias formales de indudable trascendencia, pero cuya actuación en muchas ocasiones quedaba por debajo de lo que la literalidad de las ordenanzas pudiera hacer pensar. En temas de gobierno referidos a Navarra, muchas decisiones se tomaron a través de las Juntas de la etapa austriaca, de las Secretarías de Despacho de la etapa borbónica, derivadas de la Secretaría de Despacho Universal creada por Felipe IV en 1621, del Consejo de Estado, o del Consejo y Juntas de Hacienda. Y esto tanto en el periodo de los Austrias como en el de los Borbones.

\section{I.2. El Consejo real de NAVARRA.}

\section{I.2.1. Organo gubernativo.}

Será el único del sistema polisinodial de la monarquía española que no resida en la corte, pues como institución existente en el momento de la incorporación de Navarta a Castilla, permanecerá en el Reino en virtud del juramento de Fernando el Católico -que sus sucesores mantendrán- de respetar los Fueros, leyes, usos y costumbres del pais.

Aunque en las condiciones de unión de Navarra a Castilla en las Cortes de Burgos de 1515, se señala al Consejo de Castilla como máximo órgano de gobierno, y como instancia suprema de apelación de la justicia contenciosa administrada por los tribunales del Reino, de forma que "las cosas tocantes a las çibdades e villas e lugares del dicho Reyno de Navarra e los vecinos dellas, conosciesen desde agora los del Consejo de la dicha reyna doña Juana nuestra señora, e administrasen justiçia a las dichas çibdades e villas e lugares del dicho Reyno e a las vecinos dellas que ante ellos vinieren a pedirla de aqui adelante, guardando los fueros y costumbres de dicbo Reynow, en realidad los asuntos de justicia contenciosa y el gobierno del territorio se administraron en gran parte a través del Consejo de Navarta.

Minusvalorar su labor política por el hecho de que su actuación estaba subordinada a la toma de decisiones regias, es desconocer el importante papel que jugó en el asesoramiento del virrey, tanto en asuntos promovidos por peticiones de reparo de agravios planteadas por las Cortes, como en otros de gobernación general resueltos por el delegado real en el ejercicio de sus atribucio-

14 Martinez ArCe, M.D.: Pamplona en el corazón. Recuerdos de algunos personajes ilustres de las s. $X V I, X V I I$ y XVII, (Colección Breve de temas pamploneses, $\mathbf{n}^{\circ} 33$ ). Pamplona: Ayuntamiento de Pamplona, 1996; y Una larga bistoria: vicisitudes de la sede de Consejo real de Navarra en Pamplona, en Príncipe de Viana, $1998, \mathrm{n}^{\circ} 214$, pp. 393-411.

Hispania, LX/2, núm. 205 (2000) 563-596 
nes, o en cumplimiento de cédulas y provisiones emanadas desde la secretaría real, o de diferentes Consejos y no solo desde el de Cámara de Castilla.

Si en palabras de Tomas y Valiente los Consejos de la corte atienen el poder que el monarca depasita o delega en ellos....por lo que no puede sorprendernos que administren justicia entre partes por via litigiosa, tomen decisiones de gobierno en cuanto a órganos jerarquicamente superiores al resto de la máquina administrativa, e incluso promulguen normas legales de vigencia más o menos general» ${ }^{15}$, el Consejo de Navarra no desmerece en atribuciones y competencias respecto a las ejercidas por otros Consejos territoriales, quedando a salvo y por encima de todo la autoridad real.

De su capacidad legislativa ejercida en colaboración con el virrey, nos queda el importante cuerpo normativo de reales provisiones acordadas entre virrey y Consejo, editadas a comienzos del s. XVII en lo que se conocen como Ordenanzas del Consejo ${ }^{16}$. Estas ordenanzas, se publicaban anualmente a comienzos de año para mantener su vigencia, como estaba establecido por la ordenanza 22 de la visita de Anaya ${ }^{17}$. Al acto de publicación asistían los miembros del Consejo, la Corte mayor, y la Cámara de Comptos.

Tales ordenanzas hacían referencia a la actuación de:

- El Regente y Consejo

- Los alcaldes de la Corte

- El semanero del Consejo y Corte

- El visitador de oficiales.

- El fiscal y abogado real.

- El sustituto del fiscal.

- Los diligencieros del fiscal.

- Los diligencieros de la Cámara de Comptos.

- El patrimonial y sus sustitutos.

- El chanciller y sello.

- El registro y el registrador.

- El alguacil mayor y sus lugartenientes.

- Los abogados.

- Los relatores.

- Los secretarios del Consejo.

- Los escribanos de la Corte.

- Las ordenanzas comunes de los secretarios del Consejo y escribanos de la Corte.

- Los escribanos de la Cámara de Comptos.

- Los escribanos reales.

- Los receptores de penas de Cámara.

is TOMAS Y VALIENTE, Fr.: Las instituciones... p. 128.

16 Ordenanzas del Consejo del Reyno de Navarra, de 1622.

17 AGN, Comptos, Papeles sueltos, leg. 53 carp. 15 (año 1769).

Hispania, LX/2, núm. 205 (2000) 563-596 
- Los comisarios receptores y sus repartidores.

- El tasador de procesos.

- El archivista y archivo.

- Los procuradores.

- Los porteros y ejecutores.

- Los ujieres.

- Los autos acordados.

De los componentes del Consejo de Navarra, el miembro más notable fue el regente, denominación que sustituye a la de presidente que utilizaba el organismo antes de la visita de Valdés. Las razones del cambio de denominación tienen que ver con la intención de desbancar al condestable de Navarra de tan importante cargo político, pues como canciller que era del Reino le correspondía por concesión de los ultimos reyes Albret en 1493, nada menos que la presidencia del Consejo. Hay que decir que estas competencias fueron de gran utilidad para los intereses castellanos en momentos tan dificiles como los que sucedieron a la muerte de Fernando el Católico, en los que la colaboración entre el regente de los reinos de Castilla (el cardenal Cisneros) y el condestable fue decisiva para inclinar la balanza hacia la sucesión del Reino en favor de Carlos de Habsburgo.

Pero tan extensas atribuciones cancillerescas resultaban excesivas cuando el poder de los Habsburgo fue incontestable, acabados los problemas bélicos y la intervención franco-agramontesa de los años 1521-1524. No interesaba de ninguna manera que la presidencia del Consejo de Navarra implícitamente ligada a las preeminencias cancillerescas, continuara en manos de persona tan mediatizadora de la política navarra como lo era el conde de Lerín, jefe de la facción beamontesa. Probablemente a consecuencia de los informes de visitador Valdés, la Corona rebajará las atribuciones del canciller de Navarra situandolas en las estríctamente administrativas que tenían los cancilleres castellanos, de forma que en 1530 se le otorgan los derechos y emolumentos del registro y sellado de los documentos reales expedidos tanto en la corte como en el propio Reino, omitiendose toda referencia a la presidencia del Consejo ${ }^{18}$.

La cualificación de los regentes que vinieron a presidir el Consejo de Navarra, y ocuparon al mismo tiempo importantes puestos en la administración castellana antes y despues de su paso por la presidencia del Consejo navarro es indudable. Hay que destacar además que una vez que salían del Reino se convertían en informadores cualificados de la situación de Navarra, que habían tenido ocasión de conocer directamente, jugando siempre las bazas favorables a los intereses de la Corona.

18 Ostolaza Elizondo, M.I.: Cancillería y registro de los docxmentos públicos en Navarra durante la etapa de los Autrias, en Príncipe de Viana, 1998, $\mathrm{n}^{\circ} 214$, pp. 433-446.

Hitpania, LX/2, núm. 205 (2000) 563-596 
Las ausencias autorizadas al virrey para dejar temporalmente el Reino, o las vacantes producidas por fallecimiento del delegado regio, eran cubiertas bien por el obispo de Pamplona, o por el regente del Consejo, a los que el soberano otorgaba autoridad para entender en los asuntos de gobernación política, aunque no en temas militares pues requerían una preparación más propia de la gente de guerra.

Durante el s. XVII una de las principales tareas que desempeñan los regentes del Consejo real de Navarra es la de sustituir al virrey en sus funciones políticas. Hay bastantes dificultades para encontrar sustitutos, incluso entre la propia regencia del Consejo, que en ocasiones y mientras llega el titular es ocupada por el oidor decano que debe realizar temporalmente suplencias virreinales. Todo ello es un síntoma más de los problemas de la monarquía para cubrir las vacantes del más alto puesto gubernativo del reino.

La capacidad gubernativa del Consejo, en colaboración con el virrey, o por sí solo es evidente. En este último caso hay que decir que el Consejo se convierte en el principal Organo de control de la vida de los pueblos y de la actividad municipal.

Ciertos asuntos de gobierno temporal que afectaban al reino (temas de religión, orden público) se controlaban a través de comisiones pesquisitorias encargadas por S.M. a miembros del Consejo de Navarra, que actuaban como jueces comisarios con poderes para recibir información «in situ» a fin de actuar judicialmente con conocimiento de causa. Con el tiempo formaron parte de estas comisiones jueces de los dos tribunales navarros (Corte mayor y Consejo).

Las Cortes se quejaron a menudo de la actuación de estos jueces comisarios, sobre todo si las investigaciones afectaban a personas y en especial si éstas formaban parte de las fuerzas vivas del Reino (es decir si eran miembros de las Cortes). Había más conformidad respecto a las comisiones encargadas de resolver asuntos criminales, en especial las alteraciones de orden público que daban lugar a violentos enfrentamientos entre villas vecinas.

Además de estas comisiones judiciales, el Consejo en aplicación de lo dispuesto en Leyes de visita, jugó un importante papel en los juicios de residencia, ejetcidos sobre los altos funcionarios de hacienda (tesorero, recibidores de las merindades) en la $1^{2}$ mitad del XVI, y desde 1536 sobre los municipios (en aplicación de las Leyes de visita emitidas por Fonseca que regulan entre otras cosas el juicio de residencia sobre los regimientos municipales). Al no poder introducirse en Navarra la figura del cortegidor, se facultó al Consejo para ejercer el control sobre la actividad de los oficiales municipales, muchos de ellos ligados a la administración de la justicia ordinaria.

Pese a las protestas de los inspeccionados, en especial de la ciudad de Pamplona que se amparaba en su amplísimos privilegios, el juicio de residencia fue de obligado acatamiento y se realizaba cada 3 años, supervisando lo referente a la gestión de la hacienda municipal, y la actuación de los alcaldes ordinarios, jurados, regidores, escribanos, alguaciles, alcaldes de mercado, merinos, susti- 
tutos de fiscal y patrimonial y porteros de las ciudades cabezas de merindad y buenas villas ${ }^{19}$. No se ejerció residencia sobre los lugares pequeños que no tenían categoría de buenas villas, lo que no las libraba de la obligación de enviar anualmente sus cuentas al Consejo ${ }^{20}$.

La buena gestión de los propios y rentas municipales permitió a la Corona hacer uso de ellos cuando fue necesario, aplicandolos a las obras de fortificación sobre todo de la ciudad de Pamplona, y en especial a la construcción de su magnífica ciudadela, considerada como una de las mejores de la época.

Peto además sirvió para que muchos pueblos pagaran con cargo a sus rentas, lo que les correspondía por el servicio de cuarteles y alcabalas, uno de los ingresos fiscales más importantes que tenía la Corona, y que se gastaba íntegramente en el Reino. La autorización para el cobro de este servicio la tenían que dar las Cortes, y como desde la $2^{\mathrm{a}}$ mitad del s. XVII tardaban bastantes años en reunirse, el virrey y el Consejo se vieron forzados a tomar medidas drásticas. Así en 1669 toman el acuerdo de que las ciudades, villas y lugates del Reino «que anteriormente ban pagado los dichos quarteles y alcavalas de sus propios $y$ rentas u otras consignaciones, que no ayan sido por repartimiento particular de personas, casas y baciendas" depositen (con la excusa de redimir los censos que habían tomado con permiso del Consejo), lo que les correspondería pagar por este concepto adelantandose a lo que votaran las Cortes ${ }^{21}$.

Y en la etapa de los Borbones se sigue esa misma línea, como puede colegirse a través de trabajo de Sesé: «Habitualmente se suele circunscribir en manuales al uso, la capacidad normativa del Consejo al becho de dar o no la sobrecarta. No queremos quitar importancia a este becho, pero las prerrogativa de carácter gubernativo de todo orden exceden y con mucho, al mero upase foralw. Junto a los libros de Reales Cédulas, se agrupan ingentes cantidades de disposiciones del Consejo, ya en forma de autos acordados (solo el Consejo), o de reales provisiones (virrey y Consejo), através de las cuales gobernó el tribunal navarro. A menudo (las reuniones en que se tomaban) los acuerdos se convertían en sínodos políticos que concluian con disposiciones, que únicamente un problema de nomenclatura pueden bacernos diferenciar de las leyes de Cortes, en lo que a su contenido se refieres, 22 .

\section{I.2.2. Organo consultivo de la Corona y su delegado en Navarra.}

Son muchas las solicitudes de información dirigidas al virrey y al Consejo de Navarra desde los Consejos de Castilla y su Cámara, Estado, Guerra, Hacienda y con menos frecuencia Inquisición. El delegado regio pese a sus im-

\footnotetext{
19 Ordenanzas, libro 4 , tit. $3, \mathrm{n}^{\circ} 3$ y 30 .

20 Ondenanzas, libro 4 , tit. $3, \pi^{\circ} 23-51$.

21 Provisión acordada del virrey y Consejo, de 1669-11-9.- Pamplona (AGN, Cuarteles y Alcabalas, leg. 2, carp. 67). Y es que en efecto no se reunieron Cortes desde los años 1662 al de 1677.

22 SESE ALEGRE, J.M².: El Consejo real de Navarra en el s. XVIII. Pamplona: EUNSA, 1994, p. 626.
} 
portantes atribuciones recogidas en las instrucciones de gobierno que acompañaban a su nombramiento, y en las que se incluían tanto las referentes a la capitanía general del reino y sus fronteras, como las propiamente políticas derivadas del cargo de gobernador real, no tenía la autonomía que cabría suponer en un principio.

Entre estas atribuciones y por orden de prioridad cabe señalar: la defensa de la religión católica frente al peligro calvinista $\left(2^{a}\right.$ mitad. s. XVI); Defensa de la frontera con Francia y especial cuidado de que Pamplona y sus fortificaciones no cayeran en manos enemigas; Impulso a la administración de justicia y facultad de conceder indultos (salvo en delitos de rebelión contra el rey o desacato a sus ministros, y los realizados con fuego y saeta); provisión de oficios menores de la administración de justicia, en especial en el ámbito municipal; preservación de patrimonio real y derechos de la real hacienda, con una gestión adecuada de los mismos reflejada en la Nómina del Reino; Convocatoria de las Cortes tras la correspondiente autorización real, de apertura del solio y lectura de la proposición real, intervención en las negociaciones de reparo de agravios y propuestas legislativas, y clausura de las Cortes.

Sin embargo en casi todos estos asuntos el virrey era o bien simple ejecutor de las disposiciones emanadas del soberano a través de los Consejos de Estado y Guerra (cuyos despachos y comisiones iban en estos casos dirigidos al virrey como capitán general), o las derivadas del monarca a través de otros consejos, en especial Castilla y Cámara, cuyas cédulas iban dirigidas en estos casos conjuntamente al virrey, regente y oidores del Consejo de Navarra.

Las pautas de gobierno y administración venían señaladas por pragmáticas, provisiones y cédulas procedentes sobre todo de los Consejos señalados, que se asesoraban a través de los informes remitidos sobre todo por el virrey como capitán general (para Estado y Guerra) o por el virrey y Consejo de Navarra para los restantes Consejos. El virrey y los oidores del Consejo de Navarra celebraban sesiones semanales de consulta para contestar a los requerimientos de información (de Cámara, Estado, Hacienda, etc). Son además relatívamente frecuentes las peticiones de información solicitadas desde la secretaría personal del monarca, por la que podríamos llamar vía reservada.

Debido a la reiteración con que eran solicitados estos informes, puede decirse que eran preceptivos, aunque su contenido no era vinculante para la autoridad soberana a la que iban dirigidos. De los cientos de peticiones de información solicitados desde la corte al virrey y Consejo de Navarra, no nos ha quedado en Navarta registro de los mismas hasta el s. XVII. Las respuestas con el parecer emitido, copiadas en los llamados Libros de Consultas del Consejo de Navarra conservados en el AGN, están en un estado bastante precario, puesto que el deterioro ha afectado al texto documental en muchos casos, y no ha podido ser paliado por la restauración realizada recientemente,

Sin embargo podemos conocer la forma en que se elaboraron esos informes, gracias a algunos originales que se han encontrado en distintas secciones del 
AGN. Van dirigidos a S.M. con el tratamiento que le corresponde, copian literalmente la real cédula de solicitud de información, a la que siguen el parecer del virrey y Consejo, aunque en ocasiones se incorpora además el del Fiscal y Patrimonial en aquellos asuntos que afectan a las rentas y patrimonio real.

En asuntos iniciados a petición de parte interesada, si el parecer es negativo se expresará de esta manera: «Parece nos que no siendo V.M. servido de otra cosa, no conviene que V.M. baga la merced que pide acerca de lo susodichos, a reserva de que «V.M. provebera lo que mas se sirva». Si se trata de asuntos iniciados de oficio, en Ia forma *En todo mandara V.M. proveer lo que sera su servicio».

Finalizan con la protocolaria fórmula de despedida, la fecha completa, la relación del virrey, regente y oidores del Consejo de Navarra con sus nombres completos y cargos, y el refrendo del secretario del Consejo.

El Consejo de Navarra es por tanto a nivel consultivo, uno más de los Consejos de la Corona, y conoce como ninguno la situación del reino, que puede contrastar con la documentación custodiada en el archivo de la Cámara de Comptos, donde se conservan desde los códigos legales más importantes (el Fuero de Navarra), las pragmáticas y provisiones de carácter legislativo emanadas desde la corte, que se ordena use pongan en la Cámara de nuestros Comptos reales de esse Reyno, donde suelen estar semejantes despachos", y por supuesto lo referente a la hacienda y patrimonio real, además de los Libros de Mercedes donde se copian todas las otorgadas por la Corona, cuyo cobro en forma de salario o merced económica se situa sobre las rentas reales en Navarra.

\section{I.2.3. Organo ejecutivo de las decisiones regias de gobierno y justicia.}

Virrey y Consejo ejecutaban las órdenes emitidas en uso de la facultad real de protección y salvaguarda que tenía su aplicación en el ámbito religioso y civil.

La protección real a la Iglesia, que se remonta a la A. E. Media, se refuerza si cabe en lo referente a la monarquía hispánica tras la celebración del concilio de Trento. La Casa de Austria se convierte en impulsora de la Contrarreforma y de la renovación de las órdenes religiosas, aunque no sin resistencia por parte de éstas a los proyectos de vida más observantes de sus reglas monásticas. En Navarra durante la $1^{2}$ mitad del s. XVI se reformaron los conventos de Franciscanos, Clarisas y Císter, aunque en algunos casos con la oposición de familias de la burguería pamplonesa que hicieron todo lo posible (incluyendo el involucrar a las Cortes en sus reclamaciones), por no perder la hegemonía que habían tenido en el acaparamiento de los cargos rectores de algunos monasterios ${ }^{23}$.

En el ámbito civil, el virrey y Consejo de Navarra actuaron ejecutívamente a requerimiento de S.M. en asuntos que tenían que ver con la protección de la

${ }^{23}$ Los Cruzat en relación con el monasterio de clarisas de Sta. Engracia de Pamplona (AGS, Libro 251, ff. 332-332v; 343v-344; 347; 355-355v; 376). 
vida, bienes y patrimonio de menores de edad, manejados por sus parientes sin otra intención que la de intervenir en su hacienda. Esta protección se extendía a los hijos de familias de la nobleza titulada navarra, que al quedar huerfanos eran trasladados a la corte para criarse bajo el amparo real, nombrandose administradores de su patrimonio ${ }^{24}$.

Igual sucedía con la administración de justicia, cuando una de las partes litigantes no era natural del reino. Las órdenes regias de impulso en la administración de justicia en asuntos de deudas reclamadas por mercaderes extranjeros contra naturales del Reino son frecuentes, pues los demandantes temían que al enviar comisionados para el cobro se pusieran impedimentos, por lo celoso que era el Fuero y las Leyes del reino respecto al enjuiciamiento de los navarros por jueces y tribunales extranjeros.

$\mathrm{Y}$ desde luego se ordenaba al Consejo que pusiera todos los medios para procurar que los posibles conflictos con instancias foráneas se resolvieran sin dilaciones, defendiendo los intereses de la Corona sobre todo en temas de interés general, como la construcción del Canal Imperial de Aragón, que como es sabido arrancaba en las cercanías de Tudela.

Asuntos todos ellos que van desde lo gubernativo a lo contencioso, y que en origen serían competencia de Consejo de Castilla y más concretamente de su sala de gobierno ${ }^{25}$. Aunque en la documentación no aparece claro si se remitieron desde este organismo, por el hecho de que archivísticamente están englobados en los Cedularios de Navarra, del fondo Cámara de Castilla.

\section{I.2.4. Organo asesor del virrey.}

El Consejo de Navarra es además órgano asesor del virrey en algunas cuestiones que tiene que ver con su cometido político. Así en Asuntos de Justicia: El virrey como delegado del soberano tenía poder para indultar todo tipo de delitos civiles y criminales, con excepción de los delitos de rebelión contra S.M., o desacato a sus ministros, o los realizados con fuego o saeta ${ }^{26}$. Sin embargo se le recomienda no actuar sin consultar previamente al Consejo, cuyos dictámenes eran de utilidad para virreyes en los predominaba su formación militar sobre la jurídica. Al mismo tiempo los oidores del Consejo, siguiendo en esto el criterio del fiscal de S.M., procuraban evitar que el indulto afectara al

24 Ana de Benavides y Navarta, hija de los marqueses de Cortes; Ana $\mathbf{M}^{2}$ de Peralta, hija de los maxqueses de Falces (AGS, Libro 252, ff. 444v-445v, y Libro 253, f. 021).

2) TOMAS Y VALIENTE, Fr.: Las instituciones...p. 137.

26 Estos últimos delitos, recogidos en el Fuero de Navarra, reflejan las duras condiciones en que se desarrollaron las guerras y asedios medievales, especialmente crueles en la guerra civil del s. $\mathrm{XV}$, con las secuelas que produjo hasta la incorporación del reino a Castilla. Ocasionaban la muerte del agredido de forma cruel, por efecto de las quemaduras, o del veneno con que se emponzoñaban las puntas de las flechas (Fuero Reducido, libro 6, titulo 10). 
levantamiento de las penas de Cámara, pues de ellas salían los recursos económicos necesarios para cubrir los gastos de las comisiones judiciales, traslados de presos, cárceles reales, etc.

Asuntos de Cortes: Las negociaciones de reparo de agravios solicitados por las Cortes del reino, y las propuestas de leyes elaboradas por la asamblea, eran negociadas por el virrey y los Tres Estados con todo tipo de argumentos, entre los que procuraban resaltarse sobre todo los políticos y jurídicos. Para lo cual el virrey era asesorado por el Consejo en pleno, aunque desde la $2^{\mathrm{a}} \mathrm{mitad}$ de s. XVI lo harán dos consultores, uno de ellos castellano (generalmente el regente del Consejo) ${ }^{27}$, y otro navarro (generalmente el oidor más antiguo del Consejo). Las Cortes por su parte estaban asesoradas por los Síndicos del reino, cuya formación jurídica no desmerecía en muchas ocasiones de la de los asesores virreinales.

Teniendo en cuenta que las Cortes se reunieron en Navarra en 75 ocasiones entre 1512 y 1828-1829, podemos deducir la importancia que tuvo el Consejo, sobre todo en los s. XVI-XVII, en las tareas de asesoramiento del virrey ${ }^{28}$. En contraposición con lo sucedido en otros reinos y principados peninsulares, donde a lo largo del s. XVII dejaron de reunirse Cortes, como sucedió en Cataluña a partir de 1632, en Valencia desde 1645, en Castilla desde 1665, y en Aragón desce 1683.

Hay que señalar que aparte de la labor meramente asesora de dos miembros del Consejo de Navarra hacia el virrey, sobre los agravios planteados por las Cortes, el Consejo de Navarra no intervino para nada en las sesiones de las mismas, ni coartó su capacidad de votación del servicio económico o militar pedido por la monarquía, ni por supuesto participó en su acción legislativa, tanto en la etapa de los Austrias como en la de los Borbones. Aunque sea salitse del periodo histórico tratado en este trabajo, es interesante constatar que la llegada de la nueva dinastía que modernizará la administración española, no repercute practicamente en la situación institucional de Navarra.

En palabras de Sesé, se puede afirmar que los asuntos tratados por el Consejo y las Cortes son distintos. Mientras la Corona dejó a las Cortes el tratamiento de un asunto especialmente conflictivo como fue el traslado de las Aduanas, que no se consiguió de hecho (tras el fracaso de los años 1717-1722) hasta el final de la primera guerra carlista, «Las Cortes dejaron en manos del Consejo casi todo lo referente al orden público, cuestiones eclesiásticas, control de publicaciones, organizaciòn interna de los tribunales, temas que podian baber sido en extremo conflicti-

27 A través de un memorial del Reino remitido al Consejo de Estado en 1637, conocemos que hasta 1561 el virrey recibía el asesoramiento del Consejo de Navarra en pleno. A partir de esta fecha, coincidence con las importantes Cortes de Sangüesa, el delegado regio fue asesorado por dos jueces del Consejo (AHN, Estado, legajo 66, ff. 120-124).

28 Floristan Imizcoz, A.: Historia de Navarra, t. 3: Pervivencia y renacimiento (1521-1808). (Temas de Navarra, $n^{0}$ 9). Pamplona: Publs. Presidencia del Gobierno de Navarra, 1994, p. 51. 
$v 0 s^{29}$. Es decir que se sigue una línea continuista respecto a la administración de la etapa austriaca.

Los resultados más evidentes de la actividad de las Cortes fueron sin duda las Leyes por ellas elaboradas. Sobre la capacidad legislativa de las Cortes, no parece quedar muy claro, o por lo menos ha sido objeto de controversia historiográfica, si las Cortes medievales en las que se fundamenta la actuación de las de la Edad moderna, tuvieron competencias legislativas. Son conocidos los criterios de Zuánavar que consideraba que las Cortes del reino se habían arrogado esta facultad en el s. XVI, lo que provocó la réplica de Yanguas y Miranda en sentido contrario. Campión y Lalinde han negado que las Cortes medievales tuvieran una actividad propiamente legislativa. M.P. Huici intuye que debieron colaborar en el proceso legislativo, aunque reconoce que no nos han llegado leyes escritas anteriores a la incorporación de Navarra a Castilla ${ }^{30}$.

En el reinado del Emperador no hay separación entre reparos de agravios y leyes de Cortes, según recoge Pasquier en las Ordenanzas...., obra recopilada por encargo del Consejo de Navarra, que provocó una fuerte reacción entre los representantes del reino que no se mostraron satisfechos sobre su contenido ${ }^{31}$. Sin embargo el punto de vista de la Corona vuelve a manifestarse en las Ordenanzas del Consejo del Reyno de Navarra impresas en Pamplona en 1622, que recogen muchas ordenanzas elaboradas por acuerdo entre el virrey y el Consejo, pero previamente solicitadas por las Cortes. Parece pues que en la primera mitad del s. XVI la colaboración legislativa entre las Cortes y el virrey y Consejo de Navarra fue bastante estrecha.

Será en el reinado de Felipe II cuando el reino tome conciencia de la necesidad de elaborar su propio cuerpo legislativo. Y comienzan a contraponerse a las facultades legislativas del rey (que se expresan a través de pragmáticas, ordenanzas del Consejo de Navarra y leyes de visita), de las derivadas de las propias Cortes. Las Cortes de Sangüesa de 1561 diferencian las peticiones presentadas por el reino, a las que quieren dar categoría de ley general decisiva que tenía que ser aprobada por el rey a solicitud de las Cortes, frente a las leyes particulares (especialmente las leyes de visita a través de las cuales el monarca controlaba el funcionamiento de los tribunales). Estas últimas según el criterio de las Cortes, debieran quedar subordinadas a las primeras. Lo cual era mucho

29 SESE ALEGRE, J.M ${ }^{\mathrm{a}}$.: El Consejo real .... p. 627.

30 ZUAZnAVAR, J.M.: Ensayo bistórico-crítico sobre la legislación de Navarra, Pamplona: reedición en (Biblioteca de Derecho Foral $n^{\circ}$ 8), Pamplona, 1966, 2 vols; YanguAS Y Miranda, J.: La Contregerigonza o refutación jocoseria del Ensayo....compuesto por D. José Zuaznávar, Pamplona, 1833; LALINDE, J: El sistema normativo navarn, Anuario de Historia del Derecho Español, 1976, $\mathrm{n}^{\circ} 40$, , pp. 85-108; HuicI, M.P.: Las Cortes de Navarra durante la E. moderna, Madrid: Rialp, 1963.

31 Ordenanzas, leyes de visita y aranceles, reparos de agravio y otstas provisioner reales del Reino de $\mathrm{Na}$ varra (libros I y II, más las correspondienter a las Cortes de Sangüesa de 1561 y Estella de 1565), Estella: Adrián de Anvers, 1557-1567. 
pedir pues se pretendía limitar la facultad legislativa del rey a la mera organización de los tribunales de justicia.

El carácter peculiar de las Leyes elaboradas por las Cortes de Navarra, requería la aprobación por el virrey de la propuesta presentada. En muchos casos y tras las consultas con el monarca, dicha propuesta era devuelta dando lugar a varias réplicas y modificaciones, de forma que las propias Cortes preferían retirar la propuesta de ley antes de aceptar las rectificaciones de la Corona. El contenido de las Leyes elaboradas por las Cortes de Navarra es por otra parte poco innovador en relación con las Ordenanzas elaboradas por el Consejo, y bastante reiterarivo, fundamentandose sobre todo en agravios reparados en torno al derecho de los navarros a disfrutar de los oficios, gracias y mercedes situadas sobre las rentas de la hacienda real en Navarra, el de ser juzgados por los tribunales del Reino, o la forma de administrar las Tablas, sacas y peajes.

Los proyectos decretados positívamente, y solo estos, fueron impresos a costa de Reino a partir de 1569. De ellos se hicieron vatias recopilaciones, pero la más conocida porque se editó de ella un buen número de ejemplares, es la de Joaquín de Elizondo que reune las elaboradas hasta 1716 siguiendo la organización temática de los libros y capítulos del Fuero Reducido ${ }^{32}$. Una buena versión de todo lo anterior más las correspondientes al s. XVIII y primer tercio del XIX la podemos encontrar en la recopilación dirigida por Vázquez de Prada ${ }^{33}$. Lo relativo a las disposiciones legales que quedaron vigentes tras la Ley Paccionada de 1841 , en la recopilación realizada en 1848 por J. Alonso, magistrado y regente de varias audiencias de Navarra, posteriormente fiscal del Tribunal Supremo, ministro de Gracia y Justicia, y diputado a Cortes por Madrid ${ }^{34}$.

Volviendo al periodo cronológico de nuestro estudio, diremos que desde mediados de. s. XVII la legislación de las Cortes fue apoyada por autos acordados del Consejo que pretendían «suscitar y excitar las leyes del reino", es decir impulsar su cumplimiento ${ }^{35}$. Curiosamente mientras que las Cortes de mediados de s. XVI y primera mitad del s. XVII se lamentaban a través de los reparos de agravios del incumplimiento por parte de las instituciones reales y sus oficiales de muchas de las leyes del Reino, cuando el Consejo de Navarra toma medidas para procurar su cumplimiento en la segunda mitad de. s. XVII, las

32 ELIzONDO, J.: Novisima recopilacion de las Leyes del Reino de Navarra, bechas en sus Cortes Generales desde el año 1512 basta 1716 indusite. Pamplona, 1736, 2\% edic. Bilbao: Herper, 1985.

33 VAzQUez De PRADA, V. (dir.): UsUnARIz GARAYOA, J. M². (coord.): Las Cortes de Navarra desde su incorporación a la Corona de Castilla. Tres siglos de actividad legislativa (1513-1829), Pamplona: EUNSA, 1993, 2 vols.

34 ALONSO, J.: Recopilación y comentarios de los Fueros y Leyes del antiguo retno de Navarya, que ban quedado vigentes despues de la modificación becha por la Ley Paccionada de 16 de agosto de 1841, (Biblioceca de Derecho Foral, $\mathrm{n}^{0}$ 5). Pamplona: Diputación Foral de Navarra-Institución Príncipe de Viana, 1964,2 vols.

35 AGN, Tribunales, Consejo, Autos acordados, libro 1 (1651-1699). 
Cortes se agravian alegando que no había necesidad de tales autos, pues ya existían en el reino leyes que regulaban tales asuntos.

Esta actitud del Consejo de Navarra que incrementa la judicialización de la actividad política, no puede entenderse sin tener en cuenta la frecuencia con que en el s. XVII los regentes del Consejo tuvieron que asumir funciones políticas al ocuparse interínamente del cargo de virrey. Pero la forma en que toman sus resoluciones, a través de autos acordados en los que interviene el Consejo en pleno, es considerada por las Cortes como una extralimitación, por lo que no dudarán en presentar el agravio correspondiente.

\section{I.3. La Cámara de CASTILLA Y OtRos CONSEJOS DE LA MONARQUía EN RE- LACIÓN CON NAVARRA.}

La cantidad de obras que los distintos tratadistas han dedicado a estas instituciones desde el s. XVII a la actualidad, aconsejan comenzar por una visión de conjunto como la que nos proporciona TOMAS Y VALIENTE, que identifica al Consejo de Castilla como columna central del Estado, consejo por antonomasia, identificado por los reyes con la simple denominación «nuestro Consejo». Desde 1598 se dividió en 4 salas, una para gobierno y las restantes para justicia. Aunque esta diferenciación entre gobierno y vía litigiosa, es decir entre lo gubernativo y lo contencioso, no es muy clara ni ofrece contornos precisos ${ }^{36}$.

La prioridad conferida a la sala de gobierno, presidida siempre por el presidente, es reflejo del predominio de lo gubernativo. En esta sala se resolvía lo concerniente a la protección del rey a la Iglesia, el buen gobierno de las universidades, y la política económica (control de tasas, provisión de pan y otros bastimentos, conservación de pósitos, fomento de la agricultura, cuidado de los montes). No solo decidía las grandes líneas de la política interior, sino que además las ejecutaba.

Como el Consejo era el órgano superior de gobierno de la monarquía, a la sala de gobierno estaban conferidas dos misiones importantísimas: velar por la puntual observancia de las leyes tanto en el propio Consejo como en los demás tribunales de justicia de Castilla, y resolver los conflictos de jurisdicción entre los diversos Consejos de la corte, o entre ellos y los órganos judiciales ordinarios (corregidores, audiencias, chancillerías). Podía administrar justicia por vía contenciosa en grado supremo, y podía avocar para sí cualquier pleito e inhibir al tribunal o juez que lo estuviera conociendo, pues por ser superior a los demás

36 TOMas y Valuente, Fr.: Las instituciones...., p. 134: "La sala de gobierno del Consejo de Castilla se ocupaba de decidir las grandes líneas de la política interior, especialmente en su vertiente económica..... lo referente a la protección del rey a la iglesia. Además debía velar por la puntual observancia de las leyes, y resolver las competencias entre los diversos Consejos de la corte, o entre cualquiera de ellos y los órganos judiciales ordinarios". 
órganos judiciales (incluídas audiencias y chancillerías), podía ejercer justicia como si la efectuara el mismo rey.

En cuanto a la Cámara de Castilla, hay varias líneas de interpretación histórica. Autores como Danvila o Colmeiro que consideran que el organismo no se consolida hasta 1588, o Macanaz que ni tan siquiera considera que se trate de un órgano distinto al Consejo de Castilla, por el hecho de pertenecer el presidente y letrados de la Cámara al Consejo de Castilla.

Por el contrario Salustiano de Dios, en un minucioso trabajo en el que trata de delimitar y definir la naturaleza y funciones de la Cámara, busca sus precedentes en la cancillería de la poridad y los escribanos de Cámara que desde Alfonso $\mathrm{X}$ a Sancho IV inicia su andadura en la administración castellana, para situar la formación de la Cámara en el reinado de los Reyes Católicos, su consolidación en los primeros años del de Carlos $\mathrm{V}$, y la ratificación de sus atribuciones en la instrucción dada por Felipe II en $1588^{37}$.

Posición más ponderada es la de Tomas y Valiente, que define a la Cámara de Castilla como rama desgajada del Consejo de Castilla, en razón de que su presidente y camatistas eran al mismo tiempo presidente y consejeros del de Castilla. Además contaba con un secretario real, que al igual que sucedía con los restantes miembros de la Cámara, no tenía dedicación exclusiva en este Consejo.

Para la mayoría de los historiadores del Derecho, la instrucción de 6 de Enero de 1588 es considerada como la de regulación definitiva del funcionamiento de la Cámara como órgano separado del Consejo de Castilla. De las 3 secretarías mencionadas en dicha instrucción, la de Patronato real proveía todos los oficios eclesiásticos sujetos a esta regalía; la de Gracia tramitaba y resolvía las peticiones de indultos, perdones, facultades de constitución de mayorazgos, licencias de naturalización y legitimación y otros asuntos considerados como marcas de soberanía. Además la provisión de oficios que no llevaban inherente poder jurisdiccional, las renuncias de oficios, y la venta de los mismos; por la de Justicia se proveían los oficios que llevaban incorporado poder jurisdiccional, es decir el de administración de justicia por vía contenciosa entre partes ${ }^{38}$.

Antes de 1588 (por lo menos en los cedularios de Navarra) se mezclan funciones del Consejo de Castilla y de la Cámara. Tambien Salustiano de Dios en el prólogo a su obra sobre la Cámara entre 1474-1530, se percata de ello, pues al hablar de las fuentes utilizadas para su estudio alude a la sección Diversos de Castilla, archivísticamente situada en el fondo Cámara del AGS. En esta sección se encuentran en realidad muchos documentos que tienen que ver con actividades de gobierno en su vertiente legislativa, económica y social. Por citar algunas de sus series documentales: Leyes y pragmáticas de gobierno; Orde-

37 DE Dios, S.: Gracia, merced y patronazgo real. La Cámata de Cartilla entre 1474-1530. Madrid:

Centro de Estadios Constitucionales, 1994, p. 210.

38 TOMas y Valiente, Fr.: Las instituciones...p. 141. 
nanzas de oficios y ciudades; Aduanas; Administración de alcabalas, tercias y otras rentas; Cría de caballos; Hermandades; Expulsión de judíos; Gitanos y galeotes ${ }^{39}$.

Frente a la abundancia de documentación recogida archivísticamente en Cámara de Castilla, no deja de sorprender que apenas se hayan conservado documentos del Consejo de Castilla en la etapa de los Austrias. Parece que muchos de sus papeles, según testimonio de 1577 «se babian entregado por orden del Consejo a ministros de S.M., a cada uno lo que queria tomarm. Lo que resulta paradójico en un reinado tan controlador como el de Felipe II, a no ser que se explique por las condiciones especiales de su gobierno en los últimos años de su vida ${ }^{40}$.

Cabe dudar si la mescolanza se debe a una incorrecta organización archivística, o más bien a la indefinición de asuntos tratados por los consejos de Castilla, Cámara y Estado en temas de gobernación y política interior. El propio Salustiano de Dios, menciona haber encontrado en el fondo Secretaría de Estado, numerosos memoriales y consultas pertenecientes a la Cámara de Castilla, justificando esta aparente disfunción en el hecho de que algunos secretarios de la Cámara lo fueran tambien del consejo de Estado. Y por el contrario los archiveros que se ocuparon del archivo de Simancas en el s. XIX, indicaron que entre los libros de Cámara de Castilla n ${ }^{\text {os }} 318-322$ correspondientes a los años 1532-1561, hay muchos registros de cartas y despachos que en realidad corresponden al consejo de Estado ${ }^{4}$.

Lo que sí parece evidente es que hasta el último cuarto del s. XVI (según testimonio de los embajadores que acuden a la corte de Felipe II), la Cámara de Castilla no comienza a ser un consejo específico, sino que los letrados camaristas eran un grupo especializado del poderoso Consejo de Castilla. En 1571 se nombra a Juan Vázquez de Salazar secretatio de Estado y Cámara de Castilla, pasando el consejo de Cámara a denominarse consejo de Cámara y Estado de Castilla, denominación que nada tiene que ver con el específico Consejo de Estado que en palabras de J.A. Escudero es «otra realidad institucional distinta aunque puede inducir a confusión ${ }^{42}$.

39 Consituyen 48 legajos que abarcan desde el s. XV-XVIII. Vid. DE LA PLAZA, A.: Guia de investigador...p. 149.

40 Idem, p. 141. La sección de Consejos Suprimidos del AHN, está formada (si se exceptuan las escribanías de Cámara) de manera predominante pos documentación de los s. XVIII y XIX, siendo poca la documentación del s. XVII, y menos la del XVI.

11 AGS, Inventario razonado de los pappeles de Estado hecho por Tomás González, canónigo de Plasencia, académico de la Historia y comisionado por S.M. para el arreglo del archivo de Simancas, Manuscrito de 1818.

42 EsCuDero, J.A.: El Consejo de Cámara y la neforma de 1588, en Administración y Estado en ta España Moderna. Valladolid: Junta de Castilla y León, Consejería de Educación y Cultura, 1999, pp. 457-482. $2^{\circ}$ edic. de la publicada en el AHDE, 647, 1997, vol. 2, pp. 925-941. 
Al tratar de delimitar las funciones de la Cámara antes de la instrucción de 1588 , vemos que en principio eran de tipo consultivo sobre asuntos de gracia y merced. La Cámara carecía de capacidad decisoria, de modo que la resolución de estos asuntos dependía de la consulta con el monarca, que era quien decidía. Pero la Cámara durante la mayor parte de s. XVI no solo entendió en asuntos de gracia y merced iniciados generalmente a petición de parte, sino que a través de ella podía el rey dirigirse por vía de oficio a otros Consejos, órganos jurisdiccionales $O$ de administración económica, solicitando información sobre temas de Cortes, gobernación, justicia o gracia.

Y ello es aplicable a todos los territorios dependientes de la corona de Castilla, como puede comprobarse a través de un formulario de Cámara que contiene documentación desde comienzos del XVI a 1567, con materias referentes a: convocatoria de Cortes; Patronato eclesiástico; concesiones de nobleza; provisión de oficios públicos; cartas de naturaleza; perdones; legitimaciones; constitución de mayorazgos; licencias, dispensas y habilitaciones; intervención de la Cámara en asuntos de justicia; mercedes; copias de escrituras; Ordenes militares; otros; documentación particular de algunos secretarios de la Cámara ${ }^{43}$.

La actuación de la Cámara por la vía de oficio cambia bastante durante el reinado de Felipe II, en el que veremos que se desarrolla por el cauce reservado al propio monarca, quien a través de sus secretarios personales solicita informes sobre los más variados asuntos y no solo sobre los de gracia y merced. En los Cedularios de Navarra se solicita con frecuencia al virrey y al Consejo de este reino en la forma eas mandamos que bien informados de todo nos enbieys particular relacion y parecer de lo que cerca dello debiamos mandar dar, para que vista se provea lo que convengas. En muchos de estos casos se ordena que el informe se remita al mismo secretario que refrendó la real cédula de la vía reservada, a fin de que el soberano pudiera decidir sobre el tema. La variedad de asuntos referentes a Navarra, tratados tanto en consulta como en forma resolutiva durante el s. XVI puede cotejarse en el microtesauro de materias elaborado en la base de datos que recoge la documentación de los cedularios de Navarra de la época ${ }^{44}$.

En el s. XVII, especialmente durante el reinado de Felipe III y Felipe IV, la actividad de las Juntas controladas por los validos distorsionará bastante la actuación de la Cámara. Aunque desde la caída de Olivares vemos actuar de nuevo a las secretarías de algunos consejos, en especial los de Cámara de Castilla y Estado, que son los de más estrecha vinculación con el soberano. No parece aventurado suponer que en temas complejos de política y gobierno, se tomen las decisiones en consulta y muchas veces con acuerdo de los miembros de estos Consejos, o de las Juntas que se constituyeron para resolver cuestiones

49 AGS, legajo 163 de Cámara de Castilla, serie Títulos rasgados. Vid. AGUIRRE LANDA, I.: Un formulario del Consejo de la Cámara de s. XVI, en Felipe 11 (1527-1598). Europa y la monarquía católica (dir. J. Marcínez Millán), 4 vols, Madrid: Ed. Parteluz, 1999, vol. 1, pp. 33-77.

44 OstolaZA, M.I.: Catálogo de documentación navarra de s. XVI en la Cámara de Castilla, (colección Historia, 3), Pamplona: Servicio Publicaciones Universidad Pública de Navarra, 1999.

Hispasia, LX/2, núm. 205 (2000) 563-596 
específicas. Reflejo documental de ello ello serían algunas pragmáticas, como por ejemplo las relacionadas con la política exterior y las deciaraciones de paz y guerra con sus graves repercusiones sobre el comercio exterior ${ }^{45}$, o sobre las represalias contra los bienes de naturales de reinos enemigos ${ }^{46}$.

Pero en relación con Navarra, no es el Consejo de Cámara el único que interviene en la toma de decisiones de envergadura. Asuntos que según los especialistas mencionados a comienzo de este trabajo eran competencia exclusiva de la Cámara, como los de Cortes, tampoco fueron tratados en exclusiva por este organismo. Mientras la convocatoria de Cortes se realizaba por la vía de Cámara, y algunos temas de reparación de agravios entran en este consejo, otras peticiones reparo de agravios son tratadas por otros consejos como el de Estado, cuyo peso será creciente a lo largo de los s. XVI-XVII, en especial en los primera mitad del reinado de Felipe IV que tanto se complicará por la guerra ${ }^{47}$. Lo que creará conflictos como el recogido por F. Barrios cuando la Cámara se enfrente con el consejo de Estado en 1654, por considerar ésta que los temas de Cortes eran de su exclusiva competencia. Pese a la resolución real favorable a la Cámara en este momento, el Consejo de Estado seguirá interviniendo en tales materias durante el reinado de Carlos $\mathrm{II}^{48}$.

Se puede decir que el Consejo de Estado es uno de los más importantes en su relación con Navarra, con cuyas instituciones establece una importante correspondencia. Esta correspondencia es de doble dirección, pues al Consejo de Estado se remiten los memoriales, informes y pareceres no solo del virrey (con todo y con ser la documentación virreinal la más sustanciosa y voluminosa, incluídos los informes en escritura cifrada) sobre la situación del Reino, los agravios presentados por las Cortes, informes del espionaje sobre Francia; tambien encontramos informes del regente del Consejo, de los visitadores enviados al Reino, de la Corte mayor sobre temas judiciales, etc.

Durante el s. XVI a partir de esta información el Consejo decidirá en asuntos de Estado, tanto de política exterior importantísima en Navarra por su proximidad a Francia (correspondencia con embajadores ante la corte francesa, guerra y paz, intervención en las guerras de religión francesas, negociaciones secretas con Enrique de Albret, y con su yerno Antonio de Borbón, salvocon-

15 1603, Licencia de comercio con Flandes (AHN, Cámara Libro. 524, ff. 096v-97); 1628, Prohibición de la Junca del Almirantazgo de entablat comercio con Inglaterra (AGN, Papeles sueltos, leg. 171, carp. 10); 1662 y 1663, Prohibición del Consejo de Guerra de comercio con Portugal (AGN, Guerra, leg. 4, carp. 45). 596.

46 AHN, Consejos, Cámara de Castilla, Secretaría de Gracia y Justicia, Libros de Decretos, $n^{\circ}$

47 AGS, legajos de correspondencia con Navarta desde 1512-1596, y a partir de esa fecha englobados con la de la Corona de Castilla hasta 1620. En el AHN, Estado, libros 66-68, sobce las complicadas Cortes de 1637, y otra correspondencia de tiempo de! conde-duque de Olivares.

4B Barrios, F.: El Consejo de Estado. de la monarquía española (1521-1812), Madrid: Consejo de Estado, 1984, p. 259.

Hispania, LX/2, núm. 205 (2000) 563-596 
ductos, requisa de propaganda antiespañola impresa en Francia, asunto de Antonio Pérez, etc).

Tambien en asuntos de política interior (temas relacionados con las Cortes y sus planteamientos de reparación de agravios, la sucesión del Reino, el juramento de fidelidad a la Corona, instrucciones para la administración de justicia, cumplimiento y ejecución de lo dispuesto en las leyes de visita, asuntos relacionados con la real hacienda, emisión de moneda, comercio exterior, tribunal del contrabando, etc).

Temas relacionados con el ejército y la guerra (nombramiento de oficios, nóminas, obras y fortificaciones, armamento y munición, movimientos del ejército francés en Italia y Norte de Francia, vigilancia de la frontera), jornadas contra Francia.

Tambien interviene en asuntos que en principio deberían ser competencia de otros Consejos: Así ciertos temas de justicia (pleitos entre la nobleza navarra, conflictos jurisdiccionales entre jurisdicción civil y eclesiástica, recusaciones contra jueces de los tribunales en especial del Consejo). $O$ de patronato real (provisión del obispado de Pamplona, provisión de prioratos); O de gracia (perdón a los agramonteses, petición de mercedes encumbradas, confirmación de privilegios de la ciudad de Pamplona, etc).

\section{I.4. El DESPACHO DE CáMARA EN RELACIÓN CON EL REINO DE NAVARRA.}

No puede negarse una gran conexión entre Navarra y la Cámara de CastiIla. Dicha conexión pudiera parecer excesiva en función de las materias tratadas a través de este consejo, y así ha sido interpretada por algunos de los autores mencionados en el cap. inicial. Pero la cosa resulta más comprensible si nos fijamos no tanto en el contenido de los documentos, sino en la naturaleza jurídica de los decisiones tomadas por el soberano, previo informe del consejo de Cámara. Las cuales corresponden a la vía de gracia, merced y real patronato, que cuentan con secretarías específicas desde 1588 como ya se ha dicho.

Por otra parte, y esto hay que destacarlo, el Consejo de Cámara en relación con Navarra, no ejerce en exclusiva el papel de informador de la Corona, sino que el parecer sobre los asuntos es solicitado al virrey y Consejo de Navarra por otros consejos como Estado, Hacienda, etc. La respuesta con el parecer razonado y la votación correspondiente si no hay unanimidad, se remite al consejo que solicitó el informe.

El papel preponderante de la Cámara en relación con Navarra se comprende con el órgano a través del cual se emiten muchas cédulas de petición de información sobre los asuntos iniciados a petición de parte que tenían que ver con las facultades regias en gracia, merced y patronato real. Aunque tambien se actuaba de oficio especialmente en los años anteriores a 1588 como se ha señalado. Trataremos de desglosar la naturaleza jurídica de los supuestamente

Hispania, LX/2, núm. 205 (2000) 563-596 
asuntos excepcionales tratados por la Cámara en relación con Navarra, según los términos señalados por Garma y Durán, y recogidos en el cap. inicial de este trabajo.

Entre los asuntos de gracia (cabría dudar de la acepción otorgada al vocablo en los diccionarios históricos de la lengua, que la definen como don o favor que una persona hace a otra sin atender al mérito ni esperar recompensa de que lo recibe), encontramos: cartas de perdón del delito de lesa magestad, indultos de delitos cometidos contra oficiales que representan a la autoridad real, concesión de títulos nobiliarios, concesiones de señoríos y jurisdicciones, constitución de mayorazgos, ejecutorias de hidalguía, títulos de palacios de cabo de armería, derechos de asiento en Cortes, títulos de ciudad, legitimaciones, cartas de naturaleza, dispensas de aplicación de leyes, etc.

Todos ellos suponen un cambio en el status jurídico personal o de una comunidad, y adoptan la forma diplomática de reales provisiones, es decir el documento más solemne que utiliza la burocracia real. Sin embargo su concesión no está exenta de contraprestaciones en la mayoría de los casos: Así el perdón real concedido al sector agramontés entre 1523-1524, levantando las penas de muerte y confiscación de bienes a que había sido condenados los que intentaron la recuperación de reino para los Albret, está condicionado a la prestación de juramento de obediencia y fidelidad al Emperador ${ }^{49}$. No todos los agramonteses lo cumplieron, y por tanto aunque salvaron la vida porque se refugiaron en Francia, sí perdieron la hacienda que tenían al sur del Pirineo.

Lo mismo cabría decir de los indultos que levantan sentencias judiciales. En estos casos se ha cumplido una parte de la pena, se ha conseguido el perdón de la parte ofendida, y además (al menos en el caso de los indultos virreinales concedidos por expresa delegación real), se tiene constancia de la entrega de determinadas cantidades de dinero como "donativo" para ayudar al funcionamiento de la justicia.

Otro tanto puede decirse de la venta de determinadas gracias, títulos, jurisdicciones, que desde las disposiciones de la Junta Grande de Reformación de la Real Hacienda en 1630, no pueden obtenerse sin la entrega de sustanciosas cantidades económicas en forma de donativo. La voracidad de la hacienda real es tal, que no se duda en revender estas gracias cuantas veces fuera necesario, siempre que surgiera un mejor postor dispuesto a ingresar más dinero en las arcas reales, y a cargar con los gastos de devolución de lo ofertado por el comprador precedente.

En cuanto a las concesiones de títulos nobiliarios, constitución de mayorazgos, además de la limpieza de sangre, era requisito imprescindible la demostración de méritos y servicios prestados a la Corona. No tengo datos para poder

49 Estos documentos, que fueron claves para la posterior pacificación de Reino, se encuentra tecogidas en Simancas, en el fondo de Patronato real, además de registrarse en los libros de Cámara. 
afirmar que las cartas de legitimación, de naturaleza, o las de dispensa de determinadas leyes, se otorgaran previo pago de servicios económicos.

Nombramiento de Virrey: Aunque la propuesta de nombramiento se hace a través del Consejo de Estado, es cierto que en Navarra la carta de nombramiento y las correspondientes instrucciones de gobierno se tramitan a través de la Cámara. Pero esto solo se produce a partir de 1588 , con la designación para el cargo de Luis Carrillo y Toledo, señor de las villas de Pinto y Carace$n^{30}$. Y de ahí en adelante hasta el s. XIX. Por tanto la mayor parte de los vitreyes de s. XVI (para ser más concretos 19 de ellos), fueron nombrados a través del consejo de Estado.

El por qué del cambio en 1588 , se deba probablemente al hecho de la vinculación política de Navarra a la Corona de Castilla, y la inexistencia en la corte de un consejo territorial específico que tratara las cosas del Reino, cosa que no sucedía con la Corona de Aragón ni con las Indias. Por otra parte la naturaleza jurídica de la carta de nombramiento, como todas las referentes a cargos políticos y oficios corresponde a un acto de merced, por lo que no desentona su tramitación a través de la Cámara.

Cortes: Al igual que las asambleas de la Corona de Castilla, la convocatoria (en el caso de Navarra el poder dado al vitrey para ello), se hacía a través de la Cámara, que expedía asímismo determinadas cartas dirigidas específicamente a los jefes de fila de los Tres Brazos (clerecía, nobleza y universidades), a las ciudades más importantes del Reino (Pamplona, Tudela, Estella), además de otras 4 cartas en blanco, para que el virrey pudiera hacer uso de ellas si fuera necesario.

El procedimiento no tiene nada de extraño, si se considera que la convocatoria de Cortes es un acto de merced soberana solicitado por el Reino (a través de la Diputación desde el s. XVII cuando el intervalo de celebración de Cortes se dilate en exceso). Por poner algunos ejemplos de las excusas presentadas por la Corona para justificar las dilaciones, a fines de 1668 se reponde a la Diputación: «He visto vuestra carta de 8 de agosto pasado en que nos representais que siendo fuero y ley jurada por todos los señores reyes, el que en ese Reyno baya de baber Cortes de dos en dos años y que a lo menos no pase de tres, la ocurrencia de otros negocios no nos babía dado lugar a que os bagamos esta merced aunque nos la babeis suplicado repetidas vezes. Y por haberse cumplido aora seis años que no las ba abido, tenido como teneis jurado solizitar el cumplimiento de esta merced, os a sido ynescusable bolbernos a suplicar seamos serbido de bazeros esta merced, y que para este efecto se emiten los poderes necesarios en la forma que se acostumbra. Y babiendonos consultado sobre ello, nos ba parecido deciros que quedamos con toda gratitud de vuestro afecto a nuestro servicio, $y$ a deseo que teneis de que aya Cortes en cumplimiento de la ley referida, y que quando sea tiempo tendremos muy presente lo que nos representais, y tambien el amor, celo y fidelidad con que siempre este Reyno nos a serbido y sirbe para favorezerle y bazerle merced»'s!.

50 Una única excepción a la regla, el nombramiento del conde de Castro en 1546 (AGS, Cámara, Libro 251, ff. 209-209v).

"AHN, Cámara, Libro 532, f. 2v. 
Y de nuevo en 1683 , petición de la Diputación a la que se responde: «Nos representais la preçisa obligazion que teneis de solicitar la observancia de vuestras leyes, $y$ que siendo Fuero de ese Reyno aya de aver en el cortes de dos a dos años y que a lo menos no pasen de tres, son ya çinco los que an pasado sin baverse celebrado, suplicandome sea servido de favorecer ese Reyno mandando se despachen poderes. Me a pareģido deçiros que con toda gratitud y estimazion de vuestro gelo y cuidado en procurar la combacatoria de Cortes en observangia de vuestras leyes y muy en cuenta de convocarlas quando juzgare por conveniente, estando cierto que en todas ocasiones me servireis con el amor y fidelidad que siempre lo baveis bechow 52 .

En cuanto a los asuntos de merced, era requisito imprescindible la demostración de méritos y servicios a la Corona. La merced abarcaba desde el nombramiento para todo tipo de oficios públicos, a otras concesiones económicas siguadas sobre las rentas reales en el Reino, así como las exenciones fiscales otorgadas en determinados casos. Las mercedes acababan afectando a las rentas y patrimonio real, sobre cuya distribución en lo que afectaba al gasto tenía el virrey facultades delegadas del soberano, que quedaban reflejadas en la Nómina del Reino que hacía la Cámara de Comptos al finalizar las Cortes, y rubricaba el virrey. Esta Nómina debía pasar la aprobación de la Cámara de Castilla, tras cuyo trámite se daban las órdenes correspondientes a tesorería para proceder a los pagos de salarios y mercedes económicas.

En Navarra, al igual que en los restantes reinos de la Corona de Castilla, los asuntos de gracia y merced se resolvían por expediente de Cámara de Castilla. En el caso de la Corona de Aragón la Cámara estaba ligada al Consejo de Aragón hasta su desaparición con los Borbones, pasando el territorio a depender posteriormente de la Cámara de Castilla ${ }^{53}$. Las Indias tenía tambien su Cámara, incardinada en el Consejo de Indias.

La mayor parte de los asuntos de gracia, merced y patronato real era iniciados a petición de parte. Estos memoriales de petición están recogidos mayormente en el AGS, en los conocidos como legajos de Cámara, inventariados desde $1630^{54}$. Entre ellos y mezclados con las peticiones de otros súbditos de S.M., se encuentra las peticiones de los navarros, o de los que solicitaban gracias y mercedes situadas sobre plazas o rentas de Navarra.

Evidentemente antes de su resolución, la Corona se informaba pidiendo a través de una $\mathrm{R}$. C. el parecer sobre el asunto al virrey y Consejo de Navarra que lo remitian por el cauce ordinario. Este informe generalmente iba cerrado

52 AHN, Cámara, Libro 533, ff. 17-17v.

53 ARrieta Alberd, J.: El Consejo supremo de la Corona de Aragón (1494-1701), Zaragoza: Inst. Fernando el Católico, 1994, pp. 507 y ss.: Pujol AGUADO, J.A: La Corona de Aragón en la Camara de Castilla, Alicante: Secretariado Publicaciones Univ. ALicante, 1994.

34 AGS: Inventario de los hechos y papeles presentados en el Consejo de la Cámara, en la secrecaría de gracia, que están en los archivos de Simancas. Hechos por Dn. Antonio de Hoyos, caballero de Santiago, secretario del rey, visitador y superintendente de dichos archivos reales. Por mandado del rey nuestro señor Dn. Phelipe, en Simancas a 15 de Jullio de 1630. 
y sellado, de forma que su contenido no era accesible hasta la llegada a su destino. A veces se perdía por lo que el interesado tenía que reiniciar el trámite, y de nuevo otra real cédula de Cámara volvía a dirigirse al delegado real y al Consejo de Navarra para que realizaran copia de dicho informe.

Tras la consulta regia, si la decisión del soberano era favorable, se expedían la resolución a través de provisiones o reales cédulas de Cámara, que al referirse a oficios y beneficios situados en Navarra, o a mercedes económicas pagaderas con cargo a las rentas reales recaudadas en el Reino, debían ser obedecidas y cumplidas por las autoridades políticas y hacendísticas del mismo. El cumplimiento implicaba la añadidura de la diligencia de sobrecarta que efectuaba el Consejo de Navarra, trámite imprescindible para pasar a la ejecución de lo otorgado.

Además y como complemento se remitían reales cédulas para comunicar al virrey y al Consejo, 0 al tesorero de Navarra, las concesiones de oficios y mercedes económicas. Respecto a los oficios, se ordenaba a las autoridades reales o municipales estar presentes en la toma de posesión y prestación de juramento por parte del beneficiario, procurar el respeto a sus honras y preeminencias, y hacer lo posible para el cobro de los correspondientes derechos y salarios que el oficio llevaba aparejados.

En el caso de mercedes que conllevaban salarios o concesiones económicas con cargo a las rentas reales, se ordenaba al Tesorero la copia de las mismas en los Libros de Mercedes que se custodiaban en la Cámara de Comptos, y el libramiento de las cantidades correspondientes de forma que los oidores de Comptos lo anotaran en la Nómina del Reino. Y para que quedara constancia de que todo se había cumplido, desde el reinado de Felipe II se ordena remitir relación del cumplimiento, a determinados personajes definidos como «mi criado", que cabe suponer tenían estrecha vinculación con el monarca.

Entre ellos encontramos a Juan de Galarza que actua desde 1555, aunque a partir de 1561 figura como secretario real y de Inquisición, al que se remitieron justificaciones del cumplimiento de cédulas y provisiones de gracia y merced. Antonio de Arriola, criado de S.M. que actua entre 1563-1572 con el mismo cometido. Pedro de Contreras, criado de S.M. a quien vemos actuando desde 1589 a fines de siglo, como controlador del cumplimiento de cédulas y provisiones de oficios de la casa real en Navarra, administración de justicia, mercedes con cargo a la tenta de las Tablas, acostamientos, etc. Puesto que de este personaje tenemos datos que lo identifican en 1588 como «official mayor en el escriptorio de la Cámara de S.M. y su escrivano y notario publico», podemos suponer que era el responsable de la Escribanía de Cámara, y supervisaba tanto la expedición de los documentos de Cámara como los correspondientes Libros registros donde se copiaba toda la documentación que salía de esta dependencia, y se llevaba control de las rentas y mercedes en conexión con el Consejo de Hacienda.

Vemos por tanto que la principal actividad de la Cámara de Castilla en relación con Navarra, fue la de tramitar los asuntos de gracia y merced, y tras

Hispania, LX/2, núm. 205 (2000) 563-596 
informe del Consejo de Navarra y la decisión regia, la de expedir las correspondientes provisiones o cédulas para los interesados, además de comunicar las concesiones por cédula de Cámara al virrey y Consejo de Navarra o al tesorero del Reino, a fin de que pusieran los medios para que surtieran efecto.

El papel creciente de las Juntas a lo largo del s. XVII, fue relegando a la Cámara a funciones puramente administrativas, convirtiendose en vehículo de transmisión de las decisiones tomadas por las Juntas en materia de venta de gracias y mercedes. No tiene pues nada de particular que a la llegada de los Borbones, las reformas de Macanaz y Orry que instauran los decretos de Nueva Planta, den al traste con la Cámara que es suprimida entre los años 17131715, pasando a ocuparse el Consejo de Castilla y su sala de gobierno de las materias que hasta entonces había correspondido a la Cámarass.

Lo cierto es que a lo largo de s. XVII, se incluyen en los Cedularios de Cámara referentes a Navarra otro tipo de provisiones que contienen gracias excepcionales, o resuelven cuestiones conflictivas motivadas por la necesidad de allegar recursos económicos a la Corona, en cumplimiento de lo dispuesto por la Junta de Ejecución, y otras Juntas que se ocuparon de los donativos económicos. Como muestra estos ejemplos:

- 1619- Título de hidalguía supliendo defecto de probanza por pérdida de la documentación 56 .

- 1631- Conflicto sobre el oficio de mayordomo mayor del Reino ${ }^{57}$.

- 1631- Querella del marqués de Falces contra las villas de Peralta y Falces que habian comprado la jurisdicción civil y criminal que al marqués le correspondía por ser lugares de señorío. La cual se llevó «a la sala del nuestro Consejo que esta señalada para las cosas del Donativo.Y visto todo en una Junta particular que por mi mandado se bizo.... y consultado conmigo (el rey) lo que en ella se resolvió, be acordadow 58 .

- 1632- Sobre oficios y mercedes que se otorgaron al Sr. de Vértiz en compensación por los puertos secos que pasaron a la Corona. Lo que provoca conflictos con los lugares a los que afectaban los oficios otorgadados ${ }^{59}$.

Estas provisiones aparecen firmados por S.M., refrendadas por el correspondiente secretario de Cámara, y libradas por el presidente o gobernador del Consejo, y los licenciados Juan Chumacero y Carrillo, Diego del Corral y Arellano, y

\footnotetext{
3s La justificación que de todo ello da Macanaz es que el Consejo de Cámara nunca se había distinguido del de Castilla, por el hecho de la pertenencia a este Consejo de todos los consejeros de Cámara. Vid. De Dios, S: Gracia y merced...pp. 158-159, y nota 17.

36 AHN, Consejos, Secretaría de Gracia y Justicia, Libros de Navarra $n^{\circ}$ 526, ff. 258-266.

57 Idem, Libro. 528, ff. 257v-259v.

sB Idem, Libro. 528, ff. $272 \mathrm{v}-272$.

s9 Idem, año 1532, Libro. 528, ff. 227-229v.
} 
Fernando Ramírez Fariñas. Todos ellos salvo este último miembros del Consejo de Castilla, y en el caso de Ramírez Fariñas miembro del Consejo de Hacienda.

Lo menos que se puede decir de este tipo de provisiones es que se salen del cauce habitual de la Cámara, y que en esta asala para resolver las cosas del Donativo» actuan miembros del Consejo de Castilla y del de Hacienda. La participación de Hacienda parece confirmarse por la indicación de que se remita información sobre lo referente al Donativo (eufemístico nombre para suavizar lo que era simple y llanamente venta de oficios y mercedes), a «Bartolome Mancolo nuestro secretario y contador de nuestra Hacienda, que toma relacion de los efectos que ban causado los de mi Consejo que ban entendido las cosas del Donativo»60.

Esta sala resolvía los recursos planteados por agravios de terceros perjudicados por el tema de la venta de mercedes, recursos que solían solventarse en el Consejo de Castilla. De todas formas hay que ser cautos en las valoraciones sobre el tema, mientras no se conozca mejor el funcionamiento de las Juntas especiales, que suplantaron en muchas ocasiones el papel de los Consejos ${ }^{61}$.

Las quejas que suscitó el tema del Donativo de 1629-1630 debieron ser muchas, pues tal y como señala Elliott en su epílogo sobre la figura de Olivares, el conde duque tuvo que enfrentarse a toda clase de obstáculos en sus intentos de reforma de la administración: privilegios corporativos y regionales; limitaciones prácticas y legales de la soberanía regia; la inercia de unos ministros incompetentes y corrompidos; la ambición de las oligarquías urbanas; o la resistencia sañuda y aveces explosiva de los campesinos ${ }^{62}$.

Esta sala para resolver las cosas del Donativo (en los términos que aparece en la documentación), no creo que sea de la misma naturaleza que las que se crearon en 1643, tras la caída en desgracia de Olivares, y que como es sabido sustituyeton a la odiosa Junta de Ejecución. Tal y como señala Elliott, en lugar de esta Junta se instauraron 3 comisiones o salas, una para gobierno, otra para reclutamientos y la tercera para la provisión de los ejércitos de España, Italia y Flandes. Para denominarlas se utiliza el término «sala", pues al parecer había que eliminar la ominosa palabra Junta ${ }^{63}$.

Si bien es cierto que la disolución de la mayoría de las Juntas de los años precedentes significaba aparentemente el triunfo de la buroctacia consiliar, pues se restauraba la autoridad de los consejos tan menoscabada en los años anteriores, la realidad demostró que la estructura administrativa había crecido demasiado, y que las demandas que recaían sobre ella se había hecho demasiado complejas y urgentes para que el monarca se ocupara de su gestión sin ayuda ${ }^{64}$.

\footnotetext{
60 Idem, Libro. 528, ff. 224-227.

65 BaLTAR RODRIGUEZ, J.F.: Las Juntas de Gobierno en la Monarquia Hispánica (s. XVI-XVII). Madrid: Centro de Estudios Políticos y Constitucionales, 1988.

62 ELuIOTT, J.H.: El conde-duque de Olivares. El politico en una spoca de decadencia. Barcelona: Ed. Ctítica, 1990 , p. 650 .

63 Eunot, J.H.: El conde-duque... p. 622-623.

64 ELulOTT. J.H.: El conde-duque... p. 631.
} 
Respecto a la maquinaria administrativa, vemos actuat a verdaderas dinastías familiares que se desenvuelven indistíntamente entre los consejos de Castilla, Cámara y Estado, los más importantes por cuanto intervienen en el gobierno político-militar en unos momentos decisivos para la casa de Austria.

Entre ellos encontramos de nuevo a Pedro de Contreras, que ha ascendido del cargo de oficial mayor de la escribanía de Cámara que ostentaba con Felipe II, a consejero y secretario de Cámara y Estado de Castilla en 1625. Probablemente pariente suyo es Francisco de Contreras cuya trayectoria se ha señalado en párrafo precedente, y Sebastián de Contreras que en torno a 1630 es miembro adel nuestro Consejo y nuestro secretario de Cámara y Estado de Castilla», y en 1637 adel Consejo de Hacienda y su Contaduría mayor, además de secretario de Cámara y Estado» ${ }^{65}$.

Posteriormente veremos actuar como secretario de Cámara y Estado a Antonio Carnero, personaje importante de la etapa de Olivares, que consiguió sobrevivir a la caída de su mentor ${ }^{66}$.

\subsection{LA CÁMARA Y LA ADMINISTRACIÓN DE JUSTICIA.}

La Cámara actuará como incitadora de la administración de justicia, cuando los tribunales de Navarra se demoren debido a las múltiples razones que hacen a la justicia lenta y por tanto ineficaz: desde los problemas causados por recusaciones que las partes hacia alguno o varios de los jueces de los tribunales; invalidación de pruebas presentadas; incumplimiento por parte de los jueces de las comisiones encomendadas para conocer «in situ» el terreno y las situaciones contenciosas.

Son muy numerosas las $\mathrm{R}$. C. dirigidas al virrey y al Consejo, ordenandoles la agilización de los procesos, o la votación de los jueces para el pronunciamiento de la sentencia en los casos en que se había finalizado la fase de instrucción del proceso y estaba visto para sentencia. Y el que tales órdenes vayan dirigidas conjuntamente al virrey y al supremo órgano judicial del reino, tienen que ver con las competencias virreinales que le facultan para impulsar el ejercicio de la justicia, aunque el virrey como tal no intervenía en la jurisdicción contenciosa, salvo en temas militares en los que como capitán general tenía facultades superiores sobre los alcaldes de las guardas, y sobre la tropa castellana asentada en Navarra.

65 AHN, Cámara, Libro 527; AHN, Estado, legajo 67, f. 379.

66 Baltar Rodriguez, J.F.: Las Juntas de gobiemo..., pp. 237, 244, 245, 549, 577, 686, 688, $692,715,754$. Este secretario del rey fue en 1621 secretario del Consejo y Junta de Italia. Poco despues secretario particular del conde-duque, que le promociona en 1625 a la secretaría de la Junta y Tribunal superior del Almirantazgo; en 1638 miembro de la Junta de Portugal; en 1641 de la Junta de Estado de Dinamarca.

Hippania, LX/2, núm. 205 (2000) 563-596 
Pero donde verdaderamente brilla la Cámara como órgano judicial, es en la facultad que tiene para dictaminar y resolver los recursos planteados por conflictos jurisdiccionales que pudieran surgir entre las distintas instituciones y autoridades con poder jurisdiccional. Esta actividad la desempeña no solo en lo referente al reino de Navarra, sino en el conjunto de los reinos de Castilla.

El primer conflicto serio se plantea a mediados de s. XVI, entre el Consejo de Navarra y el propio Consejo de Cámara a propósito de las competencias de ambos organismos respecto a la administración de la gracia y merced real. El asunto fue peliagudo, pues se involucró en él el propio virrey duque de Alburquerque, que utilizó a las Cortes de Estella de 1556 para respaldar sus argumentos. Uno de los agravios que esta Cortes presentaron, tenía como fundamento la provisión de oficios y beneficios (en concreto el priorato de la iglesia de Puy de Estella, la capellanía de palacio real de Olite, y otros oficios de justicia) efectuados por el virrey Alburquerque, mientras que la Cámara de Castilla había nombrado para los mismos a otras personas, alguna de las cuales no era natural del Reino.

En primer lugar se dilucidaban las facultades reales (a través de la Cámara de Castilla) y las virreinales para efectuar tales nombramientos, argumentando las Cortes del reino que kel Consejo de Camara de Castilla (era) para solas las gracias y mercedes de reino de Castilla y no para gracias ni mercedes del reino de Navarraw. Cosa totalmente desproporcionada por la dependencia políticia de Navarra con Castilla. Y por cuanto el virrey se había excedido en sus atribuciones, se puso en lo sucesivo al virrey Alburquerque como modelo a no imitar, pues había basado su actuación en instrucciones que decía se le habían dado de palabra y no por escrito. No es de extrañar que desde este virreinato, la Cámara ponga especial cuidado en que las instrucciones virreinales fueran conocidas en el Reino, llegando a publicarse las otorgadas a este virrey conflictivo.

El agravio de las Cortes de Estella se fundamentaba en que se había inhibido al Consejo de Navarra para entender en los contenciosos planteados por los navarros que habían sido beneficiados por el virrey con dichos oficios y beneficios; use quito al dicbo Consejo de Navarra el conocimiento de dichas gracias y mercedes $y$ de las causas que pendian en el dicho Consejo de Navarra sobre la posesion de ellasw. Como el vicio de origen estaba en los nombramientos virreinales, los agravios no prosperaron ${ }^{67}$.

Otro de los asuntos que da lugar a presentación de recurso ante la Cámara, es el de las peticiones de reparo de agravio planteadas por las Cortes. La naturaleza jurídica de las peticiones de reparo de agravio y su posible concesión por parte del soberano o su delegado real corresponde a un acto de merced por lo que no es extraño que en los asuntos conflictivos que no se resolvieron por vía virreinal, tenga que intervenir la Cámara dictaminando en forma de auto sobre los recursos presentados. Así las Cortes de 1590 enviaron emisarios con una peti-

6) AGN, Reino, Legislación, leg. 3, carp. 3. 
ción de reparo de agravios sobre la prohibición regia de 1588 que vedaba la saca de caballos, yeguas, potros y tocines a otros reinos salvo al de Castilla. Con ella se dejaba sin efecto una ley de Cortes del Reino que pretendía fomentar la cría de este ganado, pues el criterio "de algunos del nuestro Consejo y cierta relacion y parecer que sobre ello nos embiaron por nuestro mandado el nuestro visorrey, regente $y$ del nuestro Consejo del dicho Reyno de Navarra» aconsejaba hacerlo así.

El tema tenía que ver con las prohibición de saca de cosas vedadas, y ya que las Cortes no podían agraviarse por el fondo de la cuestión, lo hicieron por la forma «diziendo no averse podido bazer la dicha probibicion si no es a suplicacion de los dicbos Tres Estados», amparandose en los fueros y costumbres del Reino. Lo cual no era descabellado pues en la $1^{2}$ mitad del s. XVI, las más importantes ordenanzas de gobierno se hicieron por provisión acordada entre el virrey y Consejo de Navarra, figurando en ellas la petición de las Cortes del Reino.

Examinados los argumentos, el Consejo de la Cámara «ba mandado declarar $y$ declara aver podido despachar las dichas sus carta y provision real de probibicion sin suplicacion de los dichos Tres Estados». Y lo declara por medio de un auto transmitido por real cédula refrendada por el secretario Juan Vázquez de Salazar en 14-5-1591. El cual es notificado a los mensajeros de las Cortes (a los que por cierto se ordena vuelvan a casa sin ocasionar más gasto al Reino), por Pedro de Contreras, oficial mayor de la Cámara.

Como los mensajeros del Reino no se dan por satisfechos y vuelven a insistir en el reparo de agravio, se obliga a elevar consulta del asunto al propio soberano por el secretario de Estado y despacho, y en consecuencia se emite un despacho real por R. C. que ordena al Consejo de Navarra el 25-5-1591 *lo guardeis, cumplays y executeys... y para que assi se baga proveais que esta nuestra cedula se ponga en la Cámara de nuestros Comptos reales de esse Reyno, donde suelen estar semejantes despachos". Lo que se realiza, sobrecarteandose el documento mediante real provisión emitida por el Consejo de Navarra el 12-6-1591, señalada por el virrey y los consejeros, dandole publicidad en forma de pliego impreso ${ }^{68}$.

Uno de los conflictos jurisdiccionales más graves se produce como consecuencia de la venta de mercedes y jurisdicciones, que involucta a la villa de Fitero en su intento de separarse del yugo señorial del monasterio de Fitero, para constituir una nueva población dependiente de la jurisdicción real. Conflicto que abarca un largo cuarto de siglo, en el que se ven mezcladas las principales instituciones del Reino (Consejo de Navarra, Cortes) y la Cámara de Castilla, cuyos autos no llegan finalmente a cumplirse, produciendo resultados poco satisfactotios.

La secuencia documental del conflicto es Ia siguiente:

- 1652-7-14.- Madrid: R.P. de Cámara que concede a la villa de Fitero 50 robadas en los montes de Cierzo y Agenzón, para una nueva población de ViLlareal, a cambio de 14.000 ducados (111.000 reales de plata).

69 AGN, Comptos, caj. 182, $\mathrm{n}^{\circ} 94$. 
- 1652-7-20: Petición por parte de la villa al Consejo de Navarra, de sobrecarta de esta merced, para proceder a su ejecución. El Consejo la comunica al Reino que estaba reunido en Cortes, y al monasterio de Fitero, ciudades de Corella y Cascante y villa de Cintruénigo por si quieren presentar alegaciones.

- 1653-8-31.- Madrid: R.C. de Cámara al Consejo de Navarra, ordenando informe sobre la situación, puesto que la villa fiterana se ha quejado de que no se le ha expedido la sobrecarta solicitada.

- 1654-4-24.- Madrid: Sobrecédula al Consejo de Navarra, ordenandole sobrecartear la cédula y despachos referentes a la R.P. inicial (entre ellas una R.C. de 1653-8-31; otra de 1654-8-24; y otra de 1654-11-8, en la que desoyendo la súplica del monasterio de Fitero a la Cámara «sin perjuicio del convento de litigar en justicia», se ordena dar posesión a la villa de los términos concedidos, facultandole para disponer de los arbitrios necesarios para pagar a la hacienda real la cantidad ofrecida.

- 1654-11-8.- Pamplona: Informe del Consejo sobre el asunto. Se indica que la concesión suponía la revocación de una merced anterior otorgada por el virrey conde de Oropesa en 1643, que había otorgado al monasterio los mismos montes a cambio de 2.000 ducados para paliar las necesidades militares; el monasterio y las ciudades y villas mencionadas plantean pleito ante el Consejo de Navarra alegando sus derechos particulares y comunales; El estado de pleito a fines de Abril del año en curso estaba visto para sentencia, a falta de realización de una vista ocular de los términos y montes contenciosos que se había ordenado por comisión al oidor Juan de Torres y Armendáriz, que no la había cumplido alegando primero una enfermedad y posteriormente su traslado a la plaza de alcalde de casa y corte para la que acababa de ser nombrado; el nuevo juez comisionado Jerónimo de Feloaga tambien había dado largas al cumplimiento de su comisión.

- 1655-3-16.- Madrid: R.C. con el auto de Cámara de Castilla ordenando al Consejo de Navarra cumplir la provisión inicial y cédulas posteriores, expidiendo sobrecarta y dando posesión de lo otorgado a la villa.

- 1655-7-6.- Pamplona: Informe negativo del Consejo de Navarta, tras realizarse la vista ocular de los términos contenciosos, complicandose la situación porque la villa por su cuenta y riesgo había procedido al amojonamiento y levantamiento de planos de la nueva población, afectando entre otros al término de Olivarete que era propiedad del monasterio, y a los despoblados de Turujén y Niencebas, concedidos en el s. XII por Alfonso VII de Castilla al monasterio y localidades de Cintruénigo, Agreda, Corbera, Cascante y S. Pedro de Yanguas.

El parecer del Consejo de Navarra es que se debía sobreseer la concesión de 1652, y el auto de Cámara de 1655.

- 1658-12-15.- Madrid: Sobrecédula de un decreto de Cámara de Castilla de 1658-5-13, que ordena al Consejo sobrecartear la provisión inicial y las 4 
R.C. posteriores $(1653,1654,1654,1655)$, aunque trasladando la nueva población a una legua de distancia del monasterio de Fitero.

-1659-5-27.- Pamplona: Informe del Consejo de Navarra recogiendo las alegaciones de la Diputación del Reino. Votan en contra de lo ordenado por la Cámara el virrey y 3 oidores; votan a favor de la Cámara 2 oidores.

-1660-6-9.- Tolosa: R.C. con un decreto de la Cámara ordenando sobrecartear la provisión incial (como ya se había decretado en la sobrecédula de fines de 1658), y que en su conformidad y de lo resuelto por el mi Consejo de la Cámara por los autos por él proveídos, sin embargo de lo dicho y alegado por el convento de Fitero y la Diputación, se de la sobrecarta solicitada y se permita la posesión de dichos términos" ${ }^{69}$.

El asunto tiene visos de acabar favoreciendo los intereses de la villa, que ya había pagado la mayor parte de la cantidad ofrecida, pues en 1665 la villa de Fitero se une a las restantes que planteaban litigio. Pero no se acaba de pagar la cantidad estipulada para la compra de la jurisdicción criminal, que es adquirida por el monasterio de Fitero en 1657 ofreciendo más dinero a la hacienda real. La indignación de los vecinos es tal que se produce un motín y el saqueo del monasterio, pese a lo cual la villa no conseguirá su emancipación del señorio monástico hasta 1836, como consecuencia de la Desamortización eclesiástica.

\section{CONCLUSIONES:}

De todo ello podríamos concluir que la Cámara de Castilla en relación con Navarra tuvo competencias de indudable importancia, pues a través de ella discurrían los asuntos de naturaleza de gracia, merced o patronato real. Pero no se observa en el tratamiento dado a Navarra diferencia alguna respecto al otorgado a otros reinos y territorios de la Corona de Castilla.

No puede sobrevalorarse la actuación de la Cámara en temas de política y gobernación del territorio, en los que el papel de otros consejos en especial el de Estado y Guerra será fundamental como por otra parte es lógico considerando la situación estratégica del Reino en relación con uno de los más enemigos más perseverantes de la monarquía hispánica, el reino de Francia.

La efectividad de muchas de las disposiciones de la Cámara especialmente en materia de gracia y merced que lleva aparejada la disponibilidad de las rentas del Reino, fue quedando en papel mojado por el desbarate de la real hacienda en el s. XVII, con los sucesivos planes que pretendían allegar recursos extraordinarios. Pero tampoco la situación navarra será diferente a la de otros territorios.

6 Vid. AGN, Tribunales, Libros de Adronon., $\mathrm{n}^{\circ} 3$, ff. 52-54, 76v-86, 218v-219v; y AHN, Ljbros de Cámara 530, ff. $405-405 \mathrm{v}$ y 531, ff. 225-227v.

Hispenia, LX/2, núm. 205 (2000) 563-596 
En cuanto al cumplimiento de los los autos y decretos judiciales que trataban de resolver conflictos jurisdiccionales, o los provocados por la venta de mercedes al mejor postor, los resultados fueron en ocasiones poco brillantes. Las Cortes y su delegacón la Diputación del Reino, o el propio Consejo de Navarra (órgano en principio proclive a la defensa de la política real), trataron de impedir y lo consiguieron a veces, la ejecución de tales disposiciones. 